\title{
Study on the Economies of Scale in Chinese Express Industry
}

\author{
Kaixuan $\mathrm{Hu}$ \\ School of Humanities and Economic Management, China University of Geosciences, \\ Beijing, 100083, China \\ peterparkerhu@hotmail.com
}

Keywords: Express industry, Economies of scale, Industry concentration.

\begin{abstract}
The development of Chinese express industry from the Express Industry Development Index (EIDI) has been analyzed which indicates Chinese express business grow rapidly and exist economies of scale. Then this paper analyzes the economies of scale in express industry from -input factors and output factors, the result exhibits express industry is in increasing returns scale. However, industry concentration analysis shows there is still in a fierce competition among the China's express delivery industry, and leading industry is difficult to maintain absolute dominance, express delivery industry structure is reconstructing. Therefore, Chinese express industry is still in a weak economy of scale and still need to speed up the scale of construction.
\end{abstract}

\section{Introduction}

In recent years, Chinese express industry has the remarkable development that total business volume rank in the first place in the world and continue to maintain a rapid growth rate. Theoretical analysis and practice show that the existence of economies of scale has an important impact on the scale of enterprises, thus affecting the rationalization of industrial structure [1, 2]. Analysis on the scale of economic characteristics of the express industry, help us to understand the scale of China express delivery industry and Implement policy adapt to Chinese express delivery industry development.

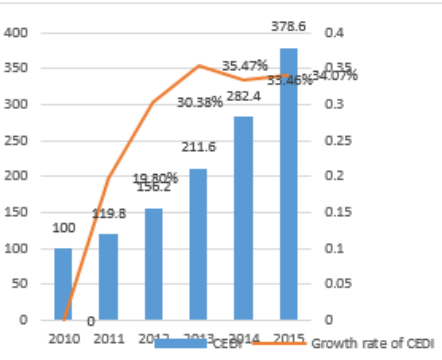

Fig. 1 The growth of CEDI

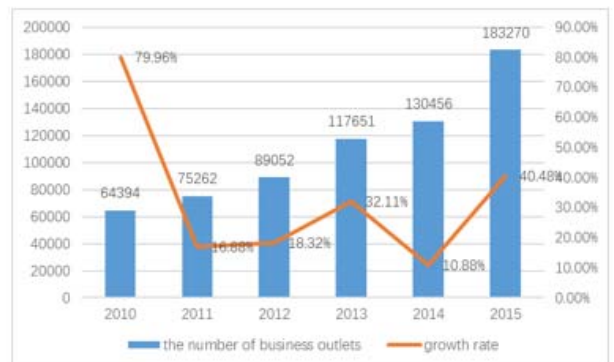

Fig. 2 Express business outlets

China State Post Bureau (CSPU) has announce Chinese Express Development Index (CEDI) from 2010. As shown above, Chinese express delivery industry has developed rapidly since 2010. From 2010 to 2015, the average growth rate of CEDI is 30.64\%, which indicate Chinese Express industry steps into a new stage where both service capacity and service upgrade comprehensively. CEDI grew fastest in 2013 reaching 35.47\% year-on-year growth. High-speed development makes it difficult for enterprises to achieve the desired economies of scale, resulting in a lot of waste of resources. So, this article will analyze the Chinese express market from the perspective of express economies of scale. To evaluate the effect of economies of scale, we usually select some indicators such us the enterprise size, return on assets, concentration of industry, capital costs, production costs, market share etc[3].this paper selected input and output elements and market concentration indicators as representatives to do the research 


\section{Analysis on Input and Output Factors}

In this part, we selected express business outlets as the input elements, express business outlets refer to the collection and delivery of goods and various types of institutions and facilities, including express delivery centers at all levels, courier nodes using for receiving and delivery are constructed by the courier companies[4]. Construction of business outlets will greatly enhance the express network effect, so we can use the number of courier nodes to carry out research. In the other hand, business income and business volume are chosen as the output factors, for the direct response to the benefit brought by economies of scale.

\subsection{Express Business Outlets.}

In order to meet the increasing domestic demand for express delivery, Chinese express companies invest a lot of money for infrastructure of delivery. According to the National Bureau of Statistics data, by the end of 2015, the number of Chinese express business outlets has reached 183270 . The number of express business outlets showed a rapid growth trend, the fastest growth rate exists in 2015 reaching $40.5 \%$ year on year growth, an average growth rate is $23.7 \%$.but the growth rate of express business outlets reflects obvious volatility. In 2013, the growth rate of express business outlets began to decline, this may be due to the saturation of express business outlets in major cities of China, the next year, express companies began to speed up the construction of the network layout and facilities in rural and central and western regions, the national express service network balance continued to improve. As of the end of 2015, the central and Western Township network coverage has reached $60 \%$.

\subsection{Express Business Volume.}

In recent years, with the rapid development of China's express industry, the postal enterprises in 2016 and the country-size's Express business volume are accumulated to reach 31.82 billion, contributing 60\% year on year growth. The figure below is 2007 - 2016 express business volume growth

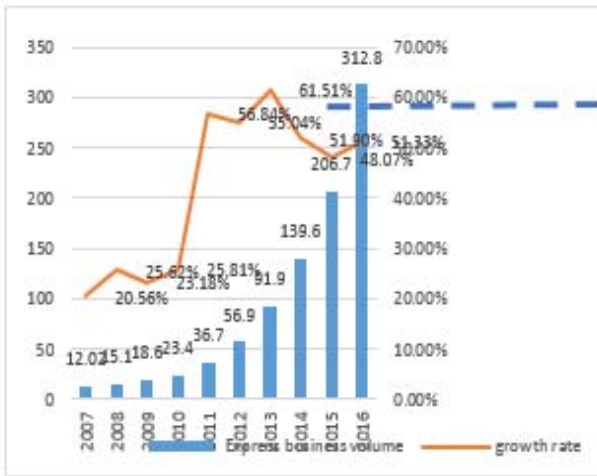

Fig. 3 Express business volume

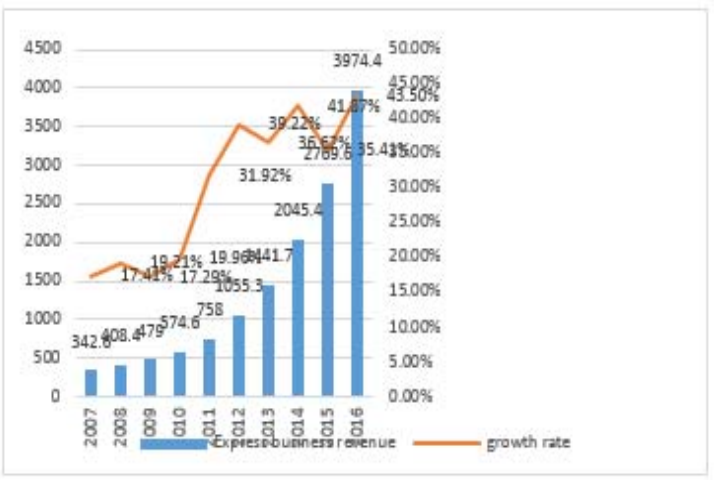

Fig. 4 Express business revenue

It can be seen from the above figure, express companies were in a stable stage of development before 2010, express business volume decline due to the 2008 financial crisis. however, since 2010, the amount of business volume growth was in explosive way that the average annual growth rate reach 54.13\%, from the beginning of 2010 China's express delivery business officially entered the stage of rapid development. The average growth rate from 2007 to 2016 was $41.99 \%$.

\subsection{Express Business Revenue}

Because of the rapid increase in express delivery volume, express delivery industry business income also showed a clear upward trend, 2016 postal and the national-scale enterprises business revenue totaled 397.44 billion yuan, increasing of 43.5\% year-on-year growth. 2007 - 2016 express business revenue growth was shown above

Like the growth in business volume, business income began to grow rapidly since 2010, but compared to the growth rate of business volume, it lag one year to reach the maximum after the growth rate of express business volume reaching in the same level. Since then growth rate has been fluctuated at $40 \%$ up and down. 2007 to 2016 average business income growth rate is $22.67 \%$, significantly lower than the average growth rate of business volume. 


\subsection{Express Business Revenue}

We have mentioned above that the input factors is the number of express business outlets, and output factors are the express delivery industry business revenue and business volume, we will define the number of express business outlets as IP 1 . The growth rate of express business income as $\mathrm{OP}_{1}$ and the growth rate of express delivery business volume as $\mathrm{OP}_{2}$. Then we select the same period (2010-2015) of these three indicators to make a comparison.

\begin{tabular}{c|ccccccc}
\multicolumn{8}{c}{ Table 1 . The growth of input-output factors } \\
\hline $\mathrm{IP}_{1}$ & $\mathbf{2 0 1 0}$ & $\mathbf{2 0 1 1}$ & $\mathbf{2 0 1 2}$ & $\mathbf{2 0 1 3}$ & $\mathbf{2 0 1 4}$ & $\mathbf{2 0 1 5}$ & Average \\
$\mathrm{OP}_{1}$ & $19.96 \%$ & $16.88 \%$ & $18.32 \%$ & $32.11 \%$ & $10.88 \%$ & $40.48 \%$ & $33.11 \%$ \\
$\mathrm{OP}_{2}$ & $25.81 \%$ & $31.92 \%$ & $39.22 \%$ & $36.62 \%$ & $41.87 \%$ & $35.41 \%$ & $34.17 \%$ \\
& $56.84 \%$ & $55.04 \%$ & $61.51 \%$ & $51.90 \%$ & $48.07 \%$ & $49.86 \%$
\end{tabular}

From the above table, we can see that the growth rate of IP1 is less than the average of output factors OP1 and OP2, the output growth rate is greater than the input growth ratio, so we can speculate that the current Chinese express market is still in the increasing returns to scale.

\section{Express Industry Concentration}

\subsection{Introduction of Concentration}

The competitiveness of the industry related to the use of economies of scale, the different use of economies of scale form a different market structure [4]. China chose use CR8 and $\mathrm{CR}_{4}$ these two indicators to evaluate the development of express delivery industry. From the general trend of economic development in the world, the degree of concentration has gradually expanded, leading to a few large enterprises is dominant in that industry. This is because the expansion of enterprise scale is conducive to the realization of economies of scale. China's express delivery industry has a different law of development, as shown below, China's express delivery industry CR8 index is declining year by year, from $81.5 \%$ in 2010 fell to $76.7 \%$ in 2016 . The concentration decline averagely $1 \%$ per year.

\subsection{Analysis on Express Industry Concentration}

The above analysis shows that the concentration of China's express delivery industry has abnormal phenomenon, business concentration dose not grow with the rapid development of the express delivery industry, but exist a downward trend, and following reasons explain such phenomenon.

\subsubsection{Leading Company's Monopoly Decline}

$\mathrm{CR}_{4}$ reflect the top four companies accounted for the proportion of market share. CR4 dropped, with an average decline of 5.9\% per year, from 64.7\% in 2010 to 50.4\% in 2015, In order to research the degree of monopoly for leading company, we calculate the proportion that the companies, ranked from five to eight, accounted for ,We define that proportion as CR4'.

$\mathrm{CR}_{4}{ }^{\prime}=\mathrm{CR}_{8}-\mathrm{CR}_{4}$

Next we compare the contribution between $\mathrm{CR}_{4}$ and $\mathrm{CR}_{4}$ ' towards $\mathrm{CR}_{8}$ to analyze the changes in industry monopoly status for the express industry.

\begin{tabular}{|c|c|c|c|c|c|c|}
\hline & 2010 & 2011 & 2012 & 2013 & 2014 & 2015 \\
\hline CR4' & $16.0 \%$ & $21.1 \%$ & $23.3 \%$ & $30.1 \%$ & $34.5 \%$ & $34.8 \%$ \\
\hline CR4 & $84.0 \%$ & $78.9 \%$ & $76.7 \%$ & $69.9 \%$ & $65.5 \%$ & $65.2 \%$ \\
\hline
\end{tabular}

In 2010, the top four companies contributed $84.0 \%$ to the $\mathrm{CR}_{8}$ index, however, $\mathrm{CR}_{4}{ }^{\prime}$ contribute more and more to $\mathrm{CR}_{8}$ index from $16 \%$ in 2010 to 34.8\% in 2015, which indicating that the gap among top eight company is shrinking. Industry monopoly decline continuously

\subsubsection{Fierce competition}

Express industry's rapid development lured a large number of enterprises to enter the express delivery industry, such as logistics enterprises Depp on, as well as E-business enterprises JD. Which is bound to intensify the competitiveness of the express industry, reconstruct the express market share of the industry, resulting in the decline in the concentration of express business.

From 2010, the average annual growth rate of express delivery business volume reached 54.13\%. In the same period, the average increase in express delivery revenue was $38.09 \%$, the gap between 
average growth rate of express delivery volume and the average growth rate of revenue has reached $16.03 \%$. With operating costs rising, express companies’ profits have been compressed.

Recent years, the average unit price drop sharply, we can further see that the express business is facing fierce competition. In 2010, an average unit price was 24.6 yuan, while dropped to 13.4 yuan in 2015. The average annual of unit price drop so fast (11.4\%) that leading industry is difficult to maintain the status of monopoly.

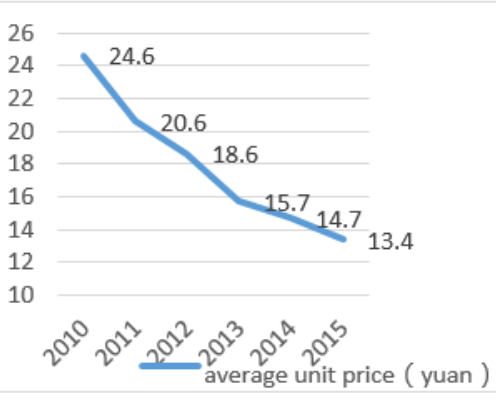

Fig 5. The variation of average unit price

\section{Conclusion}

After analysis on express delivery industry input and output factors, as well as express delivery industry concentration

We can speculate that China's express delivery industry has now appeared in economies of scale, existing increasing return to scale but having not yet reached a full scale of economic stage. Concentration analysis shows that China is currently in a weak stage of economic stage, there is no dominant enterprise can have an absolute influence on market. Express companies should continue to merger and acquisition to improve equipment utilization to form economies of scale.

\section{References}

[1]. Xiangwen Xiang. 'Discussion on the Effect of Express Network'. Journal of Beijing Jiaotong University 2012, (10): 51 - 57.

[2]. Paulos Ashebir Lakew. "Economies of traffic density and scale in the integrated air cargo industry: The cost structure of FedEx Express and UPS Airlines”. Journal of Air Transport Management. 2014. ( 35) :29 - 38

[3]. Yu Guo. Kehu Qiang; 'Express Industry Scale Economy and the Development of China's Express Industry’; Journal of Lanzhou University 2015.02 .184-189.

[4]. Thesis : ( Yu Lan. Research on Scale Economy of Industrial Enterprises in China.(Master, Wuhan University, China, 2015).p.13 